\title{
Diabetes-prone BioB reeding rats do not have a normal immune response when weaned to a diet containing fermentable fibre
}

\author{
RoseM arie Stillie, Rhonda C. Bell and Catherine J. Field* \\ Department of Agricultural, Food and Nutritional Science, University of Alberta, Edmonton, AB, Canada, T6G 2P5 \\ (Received 6 September 2004 - Revised 24 December 2004 - Accepted 9 J anuary 2005)
}

\begin{abstract}
Diet is known to modulate the development of diabetes in diabetes-prone BioB reeding (BBdp) rats. The objective of the present study was to determine the effect of fermentable fibre (FF) on immune function in BBdp and diabetes-resistant BioB reeding (BBdr) rats after weaning. Weanling BBdp (thirty-six to thirty-eight per diet) and BBdr rats (thirty to thirty-two per diet) were fed a nutritionally complete, semi-purified, casein-based diet containing either cellulose (control diet, $8 \% \mathrm{w} / \mathrm{w})$ or FF $(3.2 \%$ cellulose $+4.8 \% \mathrm{w} / \mathrm{w}$ inulin). At $35 \mathrm{~d}$, the small intestine was excised and lymphocytes isolated from spleen, mesenteric lymph nodes and Peyer's patches. Feeding FF to both BBdr and BBdp rats affected the production of anti-inflammatory cytokines $(\mathrm{P}=0.02)$. In $B B d r$ rats, feeding FF compared with cellulose resulted in an increased small intestinal length $(P=0.0031)$, higher proliferative (stimulation) index from both splenocytes $(P=0.001)$ and mesenteric lymph nodes $(P=0.04)$, and an increased proportion of $C D 8+T$-cells in the Peyer's patches $(P=0.003)$. We did not observe an effect of diet on the number of IgA-bearing cells in the jejunum from $B B d r$ rats. Feeding $F F$ to $B B d p$ rats did not affect the same parameters. $B B d p$ rats had both a higher proportion of $B$-cells in the Peyer's patches $(P=0.01)$ and a higher number of IgA + cells in the jejunum $(P=0.0036)$ when fed a diet containing $F F$, a response not observed in $B B d r$ rats. We demonstrate that several aspects of the $B B d p$ immune system respond differently than that of BBdr rats when challenged at weaning with FF.
\end{abstract}

BB rat: Diabetes: Dietary fibre: I mmune function: Weaning

The exact role of early diet in the pathogenesis of type 1 diabetes remains unknown. Studies of dietary intake during early life and subsequent development of diabetes in man are under way, such as the DAISY (Norris et al. 2003) and BA BY DIA B (Ziegler et al. 2003) studies, although identification of precise dietary triggers are not clear at this point in time. One recent hypothesis suggests that the timing of the introduction of grains and cereals may play a role in increasing the risk of diabetes among children who are genetically at risk for this disease (Norris et al. 2003). M odifying the diet, and thereby altering exposure to potential dietary antigens in the diabetes-prone BioBreeding (BBdp) rat and non-obese diabetic mouse, two models of autoimmune diabetes, has been shown to significantly delay or prevent the onset of diabetes (Scott et al. 1985; Elliott et al. 1988). The mechanism by which diet is protective or diabetogenic has not been clearly defined, al though the link between diet and development of diabetes strongly implicates a role for the gastrointestinal tract in its pathogenesis.

There is evidence from our laboratory and others that BBdp rats, compared to diabetes-resistant BioB reeding ( $\mathrm{BBdr}$ ) rats, may not be responding appropriately to a change in diet (dam's milk to cereal-based diet) at weaning. B B dr rats fed a non-purified cereal-based diet, as opposed to a semi-purified diet, had an increased small intestinal length, lower intestinal proglucagon mRNA (Reimer et al. 1998) and a greater $\left[{ }^{3} \mathrm{H}\right]$ thymidine incorporation in mitogen-stimulated lymphocytes (Field et al. 1999a) whereas diet did not affect these measures in B Bdp rats. Recently, the activity of intestinal enzyme invertase was reported to be increased in BBdr rats fed a cereal- or wheat gluten-based compared to a casein-based diet, while diet did not affect activity in B Bdp rats (Courtois et al. 2004a).

Components of the standard cereal-based diet, such as fibres that are degraded in the large intestine by intestinal bacteria (fermentable fibres, FF), have received limited attention in this model (Perrin et al. 2003). The cereal-based diet contains some FF, while semi-purified diets usually contain cellulose, a compound not considerably metabolised by the gut microflora. In non-diabetic animals and human subjects, changing the type of fibre in the diet alters immune function in the gastrointestinal tract and periphery (reviewed by Schley \& Field, 2002).

Early introduction of cereals to an infant at weaning (0-3 months) has recently been associated with increased islet cell autoimmunity (Norris et al. 2003). There is an abundant amount of evidence in BioB reeding rats (MacFarlane et al. 2003) and non-obese diabetic mice (Beales et al. 2003; Schmid et al. 2003) that wheat proteins, such as gluten, are diabetogenic. Cereals such as wheat contain FF, for example, $\beta$-glucans. Since FF can affect the immune system, the effects of this dietary component on BBdp rats at weaning warrants further investigation. We hypothesised that the gastrointestinal and peripheral immune system of BBdp rats would respond differently than

A bbreviations: BBdp, diabetes-prone BioB reeding; BBdr, diabetes-resistant BioB reeding; ConA, concanavalin A; FF, fermentable fibre; IFN- $\gamma$, interferon- $\gamma$; M L N, mesenteric lymph nodes; PMA, phorbol myristate acetate; TGF- $\beta$, transforming growth factor- $\beta$.

* Corresponding author: Dr Catherine J. Field, fax +1 780492 9130, email catherine.field@ualberta.ca 
$B B d r$ rats when animals were weaned to a diet containing FF. The specific objective of this study was to determine the effects of adding the $F F$, inulin, to a semi-purified, casein-based diet (FF diet), on parameters of immune function in both $B B d p$ and $\mathrm{BBdr}$ rats after weaning.

\section{Experimental methods}

\section{Experimental design and diets}

Male and female BBdr and BBdp rats were obtained from a colony maintained in the Department of Agricultural, Food and Nutritional Science at the University of Alberta. The breeding stock for this colony originated from the A nimal Resources Division, Health Protection Branch, Health Canada, Ottawa, ON, Canada. BBdr rats have a rate of diabetes of less than $1 \%$ (Like et al. 1982) and are used as a control strain. The incidence rate of diabetes in the $B B d p$ rats from this colony was approximately $60 \%$ on a cereal-based diet (unpublished results). This study was conducted in accordance with the Canadian Council of A nimal Care Guidelines and the protocol was reviewed and approved by the A nimal Policy and W elfare Committee in the Faculty of A griculture, Forestry and Home Economics at the University of A lberta.

All animals in the present study were housed in plastic shoebox cages with woodchip bedding in a temperature- and humiditycontrolled environment, on a $12 \mathrm{~h}$ light/dark cycle. Pregnant BBdr and BBdp dams were fed the control diet (Table 1). At delivery, litters were culled (when necessary) to a maximum of nine pups per litter. Pups were housed with their mother until $21 \mathrm{~d}$ old when they were weaned and randomised within a litter to one of two nutritionally complete, casein-based, semi-purified diets. The diets were identical except for the composition of the dietary fibre $(80 \mathrm{~g} / \mathrm{kg}$; Table 1$)$. The fat content and composition of the two diets was based on that of breast milk and infant formula. Rats were fed ad libitum on the diets for $14 \mathrm{~d}$ and were weighed regularly during this time. Food intake during these days was estimated by measuring the total amount of food given to each cage of weaned pups and dividing by the number of rats per cage (three rats per cage). At the end of the $14 \mathrm{~d}$, rats were anaesthetised using halothane and a blood sample was

Table 1. Composition of experimental diets $(\mathrm{g} / \mathrm{kg})$

\begin{tabular}{lcc}
\hline Ingredient & Control diet & Fermentable fibre diet \\
\hline Corn starch* & 378 & 378 \\
Casein* & 270 & 270 \\
L-Methionine* & $2 \cdot 5$ & $2 \cdot 5$ \\
Stearate† & 136 & 136 \\
Safflower oilł & 62 & 62 \\
Flaxseed oil§ & $7 \cdot 2$ & $7 \cdot 2$ \\
Cellulose* & 80 & 32 \\
Inulin|l & 0 & 48 \\
AOAC Vitamin Mix* & 10 & 10 \\
Bernhart-Tomerelli Mineral Mix* & 50 & 50 \\
Inositol* & $6 \cdot 25$ & $6 \cdot 25$ \\
Choline bitartrate* & $2 \cdot 75$ & $2 \cdot 75$ \\
\hline
\end{tabular}

*Harlan-Teklad, Madison, WI, USA.

†CanAmara, Edmonton, AB, Canada.

$\ddagger$ Tosca Foods.

$\S$ Gold Top, Edmonton, AB, Canada.

\|Quadra Chemicals Ltd, Oreye, Belgium.

For details of diets and procedures, see p. 646 taken by cardiac puncture. Rats were killed by cervical dislocation before tissue samples were collected.

\section{Lymphocyte isolation}

At necropsy, the spleen and mesenteric lymph nodes ( $M L N)$ were removed under sterile conditions and the immune cells were isolated as previously described (Field et al. 1999a). B riefly, lymphocytes isolated from the spleen and MLN were washed with a K rebs-Ringer-HEPES buffer, pelleted and reconstituted in a complete culture media (RPMI 1640 with antibiotic/antimycotic, $5 \%(\mathrm{v} / \mathrm{v})$ fetal calf serum (Gibco, Burlington, ON, Canada), $25 \mathrm{~mm}$-HEPES and 2.5 mm-2-mercaptoethanol, pH 7.4). Lymphocyte viability was assessed with trypan blue and was estimated to be $>95 \%$ (Sigma Chemical Co., St Louis, MO, USA) for all groups. Spleen cells were subjected to an additional treatment to lyse erythrocytes with a buffer containing $155 \mathrm{mM}-\mathrm{N} \mathrm{H}_{4} \mathrm{Cl}$, $0.1 \mathrm{~mm}$-disodium EDTA and $10 \mathrm{~mm}-\mathrm{KHCO}_{3}$.

The small intestine was excised from the body cavity between the stomach and the caecum and flushed with approximately $20 \mathrm{ml}$ cold, sterile Hank's balanced salt solution with $4 \mathrm{~mm}$ dithiothreitol. Peyer's patches were located visually, removed, placed in Hank's balanced salt solution containing $5 \%(\mathrm{w} / \mathrm{v})$ bovine serum albumin and $4 \mathrm{~mm}$-dithiothreitol, and pressed through a sterile nylon mesh before being processed in the same manner as cells from the MLN.

\section{Quantification of IgA + cells in the lamina propria}

A small piece of the jejunum from each rat was fixed in formalin, embedded in paraffin and later sectioned for determination of IgA by immunohistochemistry. Sections were cleared and rehydrated using xylenes and a graded series of ethanol dilutions, respectively. Endogenous peroxidase activity was blocked by covering the tissue section with $0.3 \%(\mathrm{v} / \mathrm{v}) \mathrm{H}_{2} \mathrm{O}_{2}$ for $12 \mathrm{~min}$. Sections were then covered with citrate buffer $(2 \mathrm{~mm}$-citrate buffer, $\mathrm{pH}$ $\left.6 \cdot 0,95^{\circ} \mathrm{C}, 30 \mathrm{~min}\right)$ to facilitate antigen retrieval. Non-specific binding was blocked with $20 \%(\mathrm{v} / \mathrm{v})$ goat serum made in PBS. The primary antibody (monoclonal mouse anti-rat IgA; Sigma) was applied overnight at $4{ }^{\circ} \mathrm{C}$. A fter washing, the sections were exposed to the secondary antibody (goat, anti-mouse IgG; Vector Laboratories, Burlingame, CA, USA; $20 \mathrm{~min}$, room temperature). Peroxidase reagents, avidin/biotin complex kit and a diaminobenzidine kit were used for colour development. Slides were counterstained with Harris's haematoxylin (Sigma). Control slides were subjected to the same treatment as described earlier, without addition of the primary antibody. I sotype controls for IgA were performed using mouse anti-pig CD45RA IgG 1 antibodies processed in the same manner as earlier. Non-specific staining was not observed in any of the controls. All samples were randomised and counted in a blinded manner by the same individual on a light microscope (Dialux 20; Leitz Wetzlar, Germany) at a magnification of $500 \times$. Cells found in the Iamina propria region that were positive for IgA were counted from twelve villi per sample (at four predetermined positions in three different sections).

Phenotype distribution

Lymphocyte subsets from the spleen, MLN and Peyer's patches were identified by one- and two-colour immunofluorescence 
using fluorescence-activated cell sorting as previously described (Field et al. 1999a). B riefly, mouse anti-rat monoclonal antibodies (IgG), specific for the following determinants: $0 \times 8$ (CD8 + T-cells), w325 (CD4 + T-cells), 0x42 (M acrophages), w313 (Pan T-cells), 0x12 (B-cells), 3.2 .3 (Natural Killer cells), Ox19 (CD5 + T-cells) were kindly provided by Dr Rabinovitch, University of Alberta, Edmonton, AB, Canada. CD3-fluorescein isothiocyanate-conjugated mouse anti-rat was purchased from PharM ingen (M ississauga, ON, Canada). Fluorescein isothiocyanate-conjugated goat anti-mouse IgG (Cedarlane, Hornby, ON, Canada) was used as a secondary antibody. For samples labelled with two colours, the second fluorescent label was anti-mouse phycoerythrocyn (Cedarlane). All antibodies were diluted in PBS with $4 \%(v / v)$ heat-inactivated rat serum prior to use. All samples were fixed in $1 \%(\mathrm{w} / \mathrm{v}$ ) paraformaldehyde (A nachemia Science, M ontreal, PQ, Canada) in PBS prior to acquisition and analysis (Field et al. 1999a).

\section{Mitogen stimulation}

Mitogen-stimulated proliferation of isolated lymphocytes was estimated by incubating spleen and MLN Iymphocytes $\left(1.25 \times 10^{6} \mathrm{cell} / \mathrm{s} / \mathrm{ml}\right)$ for $68 \mathrm{~h}$ in the presence or absence of concanavalin A (ConA; $5 \mu \mathrm{g} / \mathrm{ml}$; ICN, M ontreal, PQ, Canada) or phorbol myristate acetate (PMA; $20 \mathrm{ng} / \mathrm{ml}$; ICN) plus ionomycin (0.5 nmol/ml; Sigma) as previously described (Field et al. 1999a). Eighteen hours prior to harvesting, cells were pulsed with $37.5 \mathrm{kBq}(1 \mu \mathrm{Ci})\left[{ }^{3} \mathrm{H}\right.$ ]thymidine (A mersham Canada, Oakville, $\mathrm{ON}, \mathrm{C}$ anada). Cells were harvested (Filter $\mathrm{M}$ ate ${ }^{\circledR}$ harvester; Canberra Packard Canada, Mississauga, ON, Canada) and radioactivity was counted (TopCount $\mathrm{NXT}^{\circledR}$ plate reader, Microscint scintillation fluid; Canberra Packard Canada). A stimulation index was calculated for each sample as: amount of $\left[{ }^{3} \mathrm{H}\right]$ thymidine incorporation by stimulated cells per amount of incorporation by unstimulated cells.

\section{Cytokine production}

Lymphocytes isolated from the MLN, spleen and Peyer's patches $\left(1.0 \times 10^{6}\right.$ cells $\left./ \mathrm{ml}\right)$ were incubated in the presence or absence of ConA or PMA + ionomycin (same concentrations as the proliferation assay) in 1 and $2 \mathrm{ml}$ volumes. After $72 \mathrm{~h}$ of incubation, cell cultures were centrifuged ( $250 \mathrm{~g}$ for $5 \mathrm{~min}$ ) and the supernatants collected and stored $\left(-70^{\circ} \mathrm{C}\right)$ until they were analysed for $\mathrm{T}_{\mathrm{h}} 1$ (IL-2, TNF- $\alpha$, interferon- $\gamma($ IFN- $\gamma$ )), $\mathrm{T}_{\mathrm{h}}$ 2 (IL-10, IL-4) and $\mathrm{T}_{\mathrm{h}} 3$ (transforming growth factor- $\beta$ (TGF- $\beta$ )) cytokines. Cytokine concentrations were determined in duplicate using commercially available ELISA kits (BD Biosciences, Mississauga, ON, Canada), according to manufacturer's instructions. The absorbance was read at $405 \mathrm{~nm}$ using the SpectraM ax 190 microplate reader (M olecular Devices, Sunnyvale, CA, USA). For each cytokine, the concentration of the cytokine in each sample was quantified by comparison to a standard curve using recombinant cytokine standards. Cytokine detection limits were $31 \cdot 3-2000 \mathrm{pg} / \mathrm{ml}$ for IL-2, TNF- $\alpha$ and IFN- $\gamma, 1.6-100 \mathrm{pg} / \mathrm{ml}$ for IL-4, $15.6-1000 \mathrm{pg} / \mathrm{ml}$ for IL-10 and $15 \cdot 6-1000 \mathrm{pg} / \mathrm{ml}$ for TGF- $\beta$. Duplicate samples with a CV of $15 \%$ or less were used in the statistical analysis. Due to a limited amount of supernatant we were unable to run all the assays on each rat, the number of samples for which cytokines were assayed is indicated in Table 4.
Statistical analysis

All statistical analyses were conducted using the SA S (Statistical A nalysis System) statistical software (version 7.0; SAS Institute Inc., Cary, NC, USA ). D ata are expressed as mean with the standard error of the mean and $n$, which represents the number of rats from at least three different litters. Statistical significance was set at $P \leq 0.05$. Data were first examined to determine if there were any effects of sex using a three-way ANOVA for diet, sex and strain. A nimals were blocked by litter to control for litter effects. In data sets showing no sex or litter effects, data were combined and analysed using a two-way ANOVA for main effects of diet and strain. Effects of sex were only observed in the body weights and weight change of $\mathrm{B}$ ioB reeding rats, and did not affect any immunological parameters. Differences between groups were identified using least square means when an interaction occurred between the main effects.

\section{Results}

Rat characteristics

$B B d p$ rats weighed significantly $(P=0.005)$ more than $B B d r(47$ (SEM 1) g, n 73 v. 43 (SEM 1) g, n 63). However, weight change between 21 and $35 \mathrm{~d}$ of age did not differ between diet groups and rat strains. Male rats gained significantly more weight (67 (SEM 1) g, n 47) than females (57 (SEM 1) g, n 53) in all groups $(P<0.0001)$ except for the B Bdp rats fed the control diet, where weight change did not differ significantly between males (64 (SEM 3) g, n 14) and females (61 (SEM 2) g, n 21). Food intake per rat for the $14 \mathrm{~d}$ period did not differ significantly among groups (159 (SEM 5) g per $14 \mathrm{~d}$ ), calculated per cage (thirty-three total cages). Sex did not significantly affect any immunological parameters tested. The percentages of females and males were for BBdr control, 55 and 45, BBdr FF, 45 and 55, BBdp control, 61 and 39, and BBdp FF 55 and 45, respectively.

The small intestine was longer $(P=0.0031)$ for $B B d r$ rats fed the FF diet (Table 2) compared with $B B d r$ rats fed the control diet. Diet did not affect small intestinal length in BBdp rats. Spleen weight was not affected by diet in either strain, but $B B d r$ rats had a significantly greater $(P<0.0001)$ spleen weight than BBdp animals (Table 2). BBdr rats had a significantly higher $(P<0.0001)$ spleen weight $(5.4$ (SEM 0.1$) \mathrm{mg} / \mathrm{g}, \mathrm{n} \quad 47$ ) when expressed per gram body weight than did BBdp rats $(3.7$ (SEM 0.2) $\mathrm{mg} / \mathrm{g}, \mathrm{n}$ 45). Consistent with the lymphopenia in these animals, significantly fewer $(P<0.001)$ lymphocytes were isolated from the spleen and MLN of BBdp compared to $B B d r$ rats. $B$ oth $B B d r$ and $B B d p$ rats fed the $F F$ diet had significantly fewer splenocytes than the strain-matched rats fed the control diet $(P=0.026)$. The number of immune cells isolated from the Peyer's patches did not differ between diet groups or rat strains (Table 2).

\section{$\operatorname{IgA}+$ cells in the jejunal lamina propria}

In B Bdr rats (twelve per group), the number of IgA + cells within the lamina propria did not differ significantly between rats fed the control diet (48 (SEM 5) per twelve villi) v. the FF diet (58 (SEM 6) per twelve villi) (Fig. 1). However, BBdp rats fed the FF diet had a significantly higher $(\mathrm{P}=0.0036)$ number of IgA + cells (88 (SEM 
7) per twelve villi) compared to control diet-fed BBdp rats ( 42 (SEM 5) per twelve villi) or either BBdr group.

Phenotype distribution in the spleen, mesenteric lymph nodes and Peyer's patches

$\mathrm{BBdp}$ rats were $\mathrm{T}$-cell lymphopenic as defined by significantly lower proportions of T-cells (W3/13 +, CD5 + W313 + cells) in all tissues examined $(P<0.0001 ;$ Table 3$)$. This lymphopenia affected both the CD4 $+(P<0.0001)$ (Peyer's patches $P=0.04)$ and $C D 8+(P=0.0191) T$-cell subsets in all tissues examined (Table 3). Diet, however, did not significantly affect the phenotype distribution of immune cells from the spleen or $M L N$ of $B B d p$ or $B B d r$ rats. Feeding $F F$ to $B B d r$ rats resulted in a significantly higher proportion of $C D 8+T$-cells in the Peyer's patches compared to feeding the control diet $(P=0.003$; Table 3). CD $8+$ T-cells were virtually absent in Peyer's patches from $B B d p$ rats (Table 3 ). F eeding $F F$ to $B B d p$ rats resulted in a higher proportion of B-cells in the Peyer's patches compared to $\mathrm{BBdp}$ rats fed the control diet or either BBdr group (Table 3). The proportion of $C D 3+$ lymphocytes in BBdr rats was 46 (SEM 2) \% (n 14), 43 (SEM 2) \% (n 14) for the control and FF diets, respectively. CD3 was not measured in BBdp rats.

Response by splenocytes, Peyer's patch cells and mesenteric lymph node cells to mitogens

The incorporation of $\left[{ }^{3} \mathrm{H}\right]$ thymidine uptake by splenocytes (2237 (SEM 131) decays per min, n 63) and M LN (589 (SEM 104) decays per min, $n$ 52) cultured in the absence of a mitogen did not differ among groups (means are presented as combined from all groups). Splenocytes and MLN-derived lymphocytes from BBdr rats had a higher stimulation index to both ConA and PMA + ionomycin than did cells from $B B d p$ rats $(P<0.001$, Fig. 2(a) and (b), respectively). For BBdp rats, diet did not significantly affect the mitogen response of splenocytes and MLN cells (Fig. 2). Splenocytes and MLN cells from BBdr rats fed FF had a significantly higher stimulation index (37 (SEM 6), n 13, and 337 (SEM 73), n 10, respectively) after incubation with PMA + ionomycin than did splenocytes $(P=0.001)$ and $M L N$ cells $(P=0.038)$ from $B B d r$ rats fed the control diet (19 (SEM 2), $n$ 16, and 196 (SEM 28), $n$ 8, respectively) ( $P=0.001$; Fig. 2). Incorporation of $\left[{ }^{3} \mathrm{H}\right]$ thymidine by cells from Peyer's patches was not measured.

Unstimulated splenocytes and M LN did not produce IL -2, IFN $\gamma$ or TNF- $\alpha$. When stimulated with both ConA and PM A + ionomycin, splenocytes from $B B d r$ rats produced significantly more IL-2 than splenocytes from $B B d p$ rats $(P<0.0001$; Table 4). For $B B d r$ animals, the concentrations of the other $T_{h} 1$ (IFN- $\gamma$, TNF- $\alpha$ ) cytokines in supernatants from both splenocytes and MLN cells did not differ between diets (Table 4). There were no significant differences between rat strains or between diet groups in the production of IFN- $\gamma$ following PMA + ionomycin stimulation by splenocytes. M LN cells from $B B d r$ rats produced significantly more ConA-stimulated IFN- $\gamma$ than $B B d p$ rats $(P=0.004)$; however, TNF- $\alpha$ production by MLN cells did not differ by strain or diet (Table 4).

$T_{h} 2$ cytokine concentrations in supernatants from both $B B d r$ and BBdp stimulated splenocytes were significantly different between diet treatments. The production of IL-10 by unstimulated splenocytes (352 (SEM 24) pg/ml, n 58) did not differ among 
|ㅣㅣ

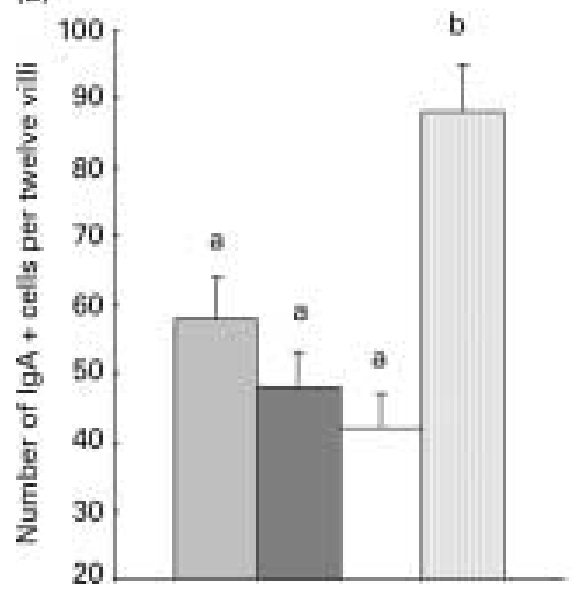

(b)

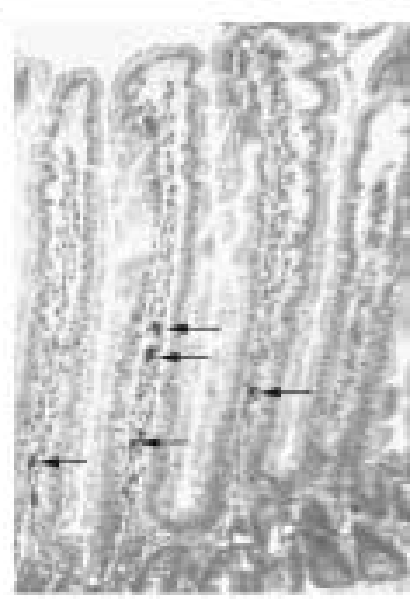

Fig. 1. The effect of diet (control v. fermentable fibre ( $F F)$ ) and strain (diabetes-prone BioBreeding rat (BBdp) $v$. diabetes-resistant $B$ ioB reeding rat (BBdr)) on the number of IgA + cells in the jejunum of BBdp and BBdr rats ( $\square$, BBdr control; $\square, B B d r F F ; \square, B B d p$ control; $\mathbb{m}, B B d p$ FF). (a), Values represent group means with their standard errors of the means depicted by vertical bars ( $\mathrm{n} 12$ ). ${ }^{\mathrm{a}, \mathrm{b}}$ Mean values with unlike superscript letters were sigificantly different $(\mathrm{P}<0.05)$. P ositively stained cells were counted in four villi per section (three sections per sample) at four equally spaced predetermined positions in the cross-section. Data were analysed by a two-way ANOVA (diet $\times$ strain) and least square means where interactions between main effects occurred. (b), Representative immunostained jejunal section from a BBdp rat fed control diet (magnification $250 \times$ ). $\leftarrow$ indicates lamina propria cells that are positive fo IgA. For details of diets and procedures, see $\mathrm{p}$. 646 .

strain or diet groups. IL -4 was not detected in supernatants from unstimulated cell cultures. ConA-stimulated IL-10 production was significantly higher in FF-fed $B B d p$ and $B B d r$ rats $(P=0.009$; Table 4) compared with those fed the control diet. Additionally, BBdr splenocytes produced significantly more IL - 10 than BBdp splenocytes $(P=0.03$; Table 4$)$. Significant effects of strain and diet were observed with PMA + ionomycin-stimulated IL-4 production, with $\mathrm{BBdr}$ cells producing larger amounts of IL -4 than $B B d p$ cells $(P=0.02 ;$ Table 4$)$, and both strains produced significantly less IL -4 when fed the FF diet ( $P=0.02$; Table 4). Stimulation of immune cells from the spleen, $M L N$ and Peyer's patches with ConA did not result in any significant differences in the production of the $T_{h} 3$ cytokine, TGF- $\beta$ (Table 4). TGF- $\beta$ was not detected in supernatants from unstimulated cell cultures.

\section{Discussion}

In the present study, we studied the response of the immune system of BBdr and BBdp rats to a dietary component known to affect the intestinal milieu by altering immunological (Field et al. 1999b; Y amada et al. 2003), morphological (Andoh et al. 1999; Kleessen et al. 2003) and microbial (K leessen et al. 2001; Buddington et al. 2002) parameters in the gut. Dietary FF is present in infant weaning foods, more notably wheat-based cereals, and is present in the weaning diets of rats. As the BBdr rats responded to the addition of $F F$ in the diet in an expected manner, $\mathrm{BBdp}$ rats showed a failure to respond appropriately to what might be considered a 'normal' dietary challenge at weaning. In diabetes-resistant rats, feeding a FF compared to cellulose resulted in an increased small intestinal length, higher proliferative (stimulation) index from both splenocytes and $M L N$, and an increased proportion of CD $8+$ T-cells in the Peyer's patches. We did not observe an effect of diet on the number of IgA-bearing cells in the jejunum from $B B d r$ rats. However, feeding FF to $B B d p$ rats did not affect the same parameters. In fact, $B B d p$ rats had both a higher proportion of B-cells in the Peyer's patches and a higher number of IgA + cells in the jejunum when fed a diet containing $F F$, a response not observed in $B B d r$ rats.
Weaning is a crucial period, immunologically, for a young animal (Cummins et al. 1989, 1991; Thompson et al. 1996). The introduction of adult foods, beginning at weaning, exposes the intestinal immune cells to more foreign protein antigens compared to dam's milk (M enezes et al. 2003), and affects the bacterial flora in the gut (Edwards \& Parrett, 2002), thereby challenging the relatively 'naive' immune system of the suckling animal. These changes drive the development of the immune system (Ouwehand et al. 2002). A ccordingly, intestinal and peripheral immune activation, such as an increase in soluble and intestinal IL-2 receptor expression, and increased intestinal inflammatory cytokine mR NA, have been reported in human subjects (Cummins et al. 1994), rodents (Thompson et al. 1996; M asjedi et al. 1999) and piglets (Pie et al. 2004), respectively, at the time of weaning.

Evidence of immune 'activation' was observed in BBdr rats fed FF after splenocytes and M LN cells were stimulated with PMA + ionomycin, but was not observed in BBdp rats. In BBdr rats, the mechanism by which feeding FF might cause increases in this response by lymphocytes to PMA + ionomycin is not known. $\mathrm{PMA}+$ ionomycin activate lymphocytes by bypassing membrane receptors. Differences observed between diet groups after PMA + ionomycin but not ConA stimulation (a mitogen that targets a lectin receptor on, or near, the $\mathrm{T}$-cell receptor) suggests that the mechanism of increased $\left[{ }^{3} \mathrm{H}\right.$ ]thymidine uptake by lymphocytes after $\mathrm{FF}$ feeding may be independent of the $\mathrm{T}$-cell receptor. PM A + ionomycin-stimulated IL-2 production by BBdr splenocytes did not differ between diets, providing further support for a T-cell receptor-independent effect. The effect of FF on the response to PM A + ionomycin may be mediated via other lymphocyte subsets, as IL -2 is produced exclusively by T-cells (W aldmann, 1993).

In both the BBdr and BBdp rat strains, feeding the FF diet increased the mitogen-stimulated production of $T_{h} 2$ cytokines in splenocytes compared with the control diet. Feeding FF to both $B B d r$ and $B B d p$ rats increased $I L-10$ production in response to ConA and decreased IL -4 production in response to $P M A+$ ionomycin. The effect of feeding FF on the ability of cells from B B dr animals to respond to mitogens has not been well characterised. A study 
Table 3. The effects of diet (fermentable fibre (FF) or control) and strain (diabetes-resistant BioBreeding (BBdr) or diabetes-prone BioBreeding (BBdp)) of rats on phenotype distribution in the spleen, mesenteric lymph node (MLN) and Peyer's patches*

\begin{tabular}{|c|c|c|c|c|c|c|c|c|c|c|c|c|c|c|c|c|}
\hline \multirow[b]{3}{*}{ Tissue } & \multirow[b]{3}{*}{ Phenotype } & \multicolumn{6}{|c|}{ BBdr } & \multicolumn{6}{|c|}{ BBdp } & & & \\
\hline & & \multicolumn{3}{|c|}{ Control } & \multicolumn{3}{|c|}{$\mathrm{FF}$} & \multicolumn{3}{|c|}{ Control } & \multicolumn{3}{|c|}{$\mathrm{FF}$} & \multicolumn{3}{|c|}{ Significancet } \\
\hline & & Mean & SEM & $\mathrm{n}$ & Mean & SEM & $\mathrm{n}$ & Mean & SEM & $\mathrm{n}$ & Mean & SEM & $\mathrm{n}$ & Diet & Strain & Diet $\times$ strain \\
\hline \multirow[t]{8}{*}{ Splenocytes } & Total T-cells (CD5 + ) & 29 & 2 & 16 & 31 & 3 & 13 & 22 & 5 & 7 & 23 & 5 & 9 & NS & NS & NS \\
\hline & Pan T-cells (W3/13 +) & 30 & 3 & 11 & 32 & 3 & 13 & 19 & 3 & 7 & 19 & 2 & 10 & NS & $P=0.0002$ & NS \\
\hline & $\mathrm{CD} 5+M 3 / 13+$ & 22 & 3 & 13 & 29 & 2 & 10 & 11 & 2 & 7 & 14 & 3 & 10 & NS & $\mathrm{P}<0.0001$ & NS \\
\hline & CD8 + (cytotoxic/suppressor) T-cells & 14 & 1 & 15 & 16 & 2 & 15 & 9 & 1 & 11 & 12 & 1 & 9 & NS & $P=0.0191$ & NS \\
\hline & CD4 + (helper) T-cells & 22 & 1 & 14 & 21 & 2 & 15 & 11 & 2 & 11 & 13 & 1 & 11 & NS & $P<0.0001$ & NS \\
\hline & $\lg +$ B-cells & 22 & 2 & 13 & 20 & 1 & 14 & 37 & 3 & 11 & 43 & 3 & 10 & NS & $P<0.0001$ & NS \\
\hline & Monocytes/macrophages & 8 & 1 & 13 & 7 & 1 & 14 & 13 & 2 & 11 & 12 & 1 & 9 & NS & $P=0.0002$ & NS \\
\hline & Natural killer cells & 9 & 1 & 14 & 7 & 1 & 14 & 8 & 2 & 7 & 13 & 2 & 9 & NS & NS & NS \\
\hline \multirow[t]{7}{*}{ MLN cells } & Total T-cells (CD5 + ) & 69 & 2 & 12 & 73 & 2 & 13 & 24 & 2 & 18 & 25 & 1 & 14 & NS & $\mathrm{P}<0.0001$ & NS \\
\hline & Pan T-cells (W3/13 + ) & 72 & 3 & 11 & 74 & 3 & 14 & 26 & 2 & 12 & 27 & 2 & 11 & NS & $P<0.0001$ & NS \\
\hline & $\mathrm{CD} 5+M 3 / 13+$ & 66 & 1 & 11 & 62 & 3 & 15 & 20 & 1 & 12 & 20 & 1 & 14 & NS & $P<0.0001$ & NS \\
\hline & CD8 + (cytotoxic/suppressor) T-cells & 20 & 2 & 14 & 20 & 1 & 17 & 6 & 1 & 14 & 4 & 1 & 12 & NS & $\mathrm{P}<0.0001$ & NS \\
\hline & CD4 + (helper) T-cells & 54 & 2 & 13 & 56 & 2 & 12 & 23 & 2 & 16 & 20 & 2 & 16 & NS & $P<0.0001$ & NS \\
\hline & Ig + B-cells & 15 & 1 & 12 & 15 & 1 & 15 & 41 & 3 & 16 & 45 & 3 & 16 & NS & $P<0.0001$ & NS \\
\hline & Monocytes/macrophages & 3 & 0.6 & 9 & 5 & 0.6 & 15 & 9 & 2 & 6 & 9 & 2 & 11 & NS & $P<0.0001$ & NS \\
\hline \multirow[t]{6}{*}{ Peyer's patch cells } & Total T-cells (CD5 +) & 22 & 2 & 7 & 24 & 1 & 12 & 10 & 1 & 9 & 9 & 1 & 11 & NS & $P=0.02$ & NS \\
\hline & Pan T-cells $(\mathrm{W} 3 / 13+)$ & 20 & 2 & 6 & 23 & 2 & 9 & 9 & 2 & 7 & 10 & 2 & 8 & NS & $\mathrm{P}<0.0001$ & NS \\
\hline & $\mathrm{CD} 5+M 3 / 13+$ & 16 & 2 & 7 & 18 & 1 & 10 & 5 & 0 & 7 & 4 & 0 & 8 & NS & $\mathrm{P}<0.0001$ & NS \\
\hline & CD8 + (cytotoxic/suppressor) T-cells & $4^{a}$ & 1 & 10 & $10^{\mathrm{b}}$ & 1 & 9 & $0^{c}$ & 0 & 9 & $1^{\mathrm{C}}$ & 0 & 9 & $P=0.003$ & $\mathrm{P}<0.0001$ & $P=0.011$ \\
\hline & CD4 + (helper) T-cells & 18 & 2 & 10 & 15 & 1 & 10 & 7 & 1 & 9 & 7 & 1 & 10 & NS & $P=0.04$ & NS \\
\hline & Ig + B-cells & $55^{\mathrm{a}}$ & 2 & 9 & $54^{a}$ & 2 & 12 & $54^{\mathrm{a}}$ & 2 & 9 & $63^{b}$ & 2 & 10 & NS & NS & $P=0.01$ \\
\hline
\end{tabular}

*Cells were obtained from BBdr or BBdp rats fed one of two similar diets differing only in the composition of fibre. Values were determined by immunofluorescence and are a proportion (\%) of total gated cells.

†P-values represent significance of main effects diet and strain analysed by a two-way ANOVA. Where an interaction occurs between diet and strain (dietxstrain) across a row, significant differences are identified by least square means and are denoted by different superscripts $(P<0.05)$.

For details of diets and procedures, see p. 646 . 


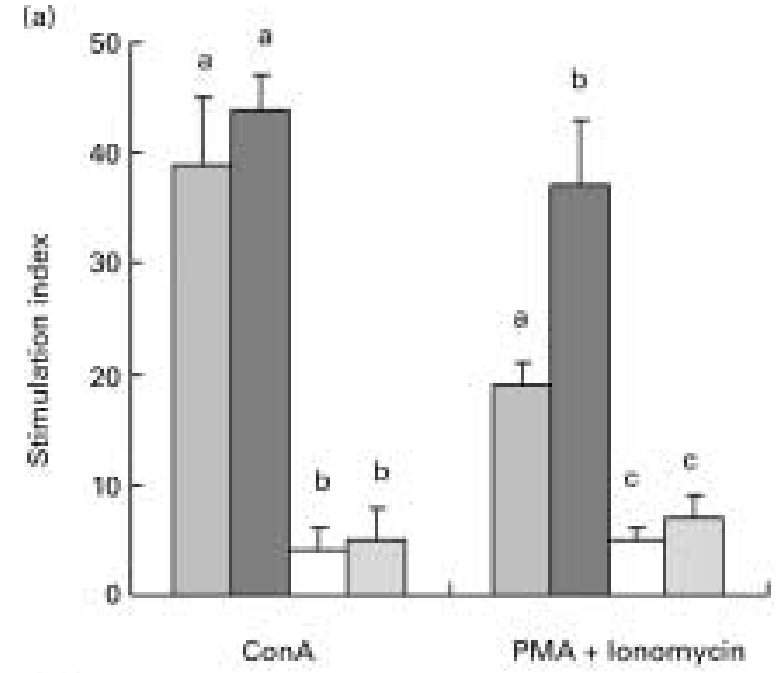

(b)

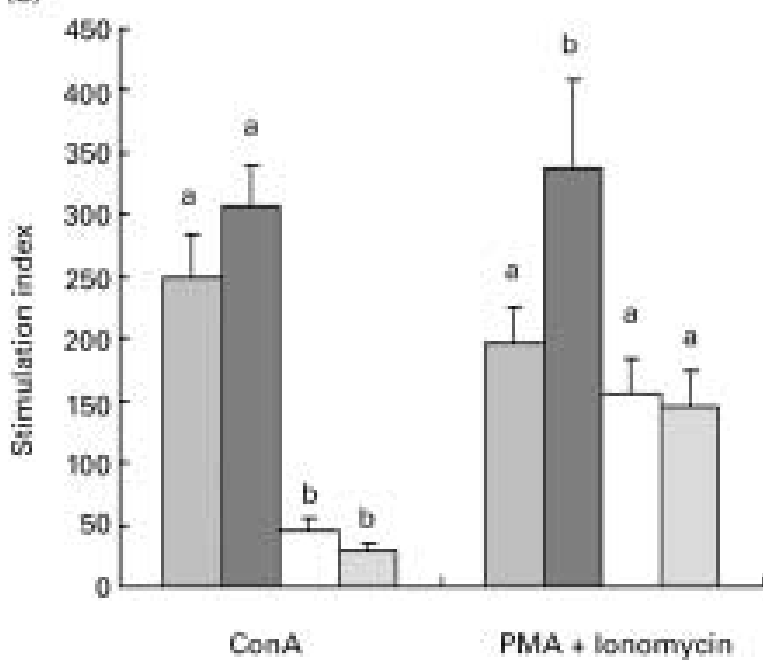

Fig. 2. The effect of diet (control v. fermentable fibre (FF)) and strain (diabetes-prone BioBreeding rat $(\mathrm{BBdp}) \mathrm{v}$. diabetes-resistant BioBreeding rat $(B B d r))$ on the uptake of $\left[{ }^{3} \mathrm{H}\right]$ thymidine by spleen (a) and mesenteric lymph node (b) lymphocytes ( $\square$, BBdr control; $\square, B B d r$ FF; $\square$, BBdp control; $\mathbb{m}$, BBdp FF). Values represent group means with their standard errors of the means depicted by vertical bars. ${ }^{a, b}$ Mean values within a mitogen with unlike superscript letters were significantly different $(P<0.05)$. Stimulation index was calculated by dividing the decays per min of stimulated cells by the decays per min of unstimulated cells. Data were analysed by a two-way ANOVA (diet $\times$ strain) and least square means where interactions between main effects occurred. ConA, concanavalin A; PMA, phorbol myristate acetate. For details of diets and procedures, see p. 646 .

by (Roller et al. 2004) found that ConA-stimulated Peyer's patch cells from rats fed inulin/fructo-oligosaccharides produced more IL -10 than cellulose-fed rats, and another study where fructo-oligosaccharides were fed to mice revealed that IL-10 production by Peyer's patch CD4 + T-cells was increased (Hosono et al. 2003). Others have speculated that diets high in FF may have an anti-inflammatory effect (Rodriguez-Cabezas et al. 2003), perhaps through the production of SCFA by intestinal microflora (A ndoh et al. 1999), and our findings support this. While feeding FF increased production of IL-10 after ConA stimulation in lymphocytes from BBdp rats, the amount of IL-10 produced was still significantly less than that observed from lymphocytes from BB dr rats.

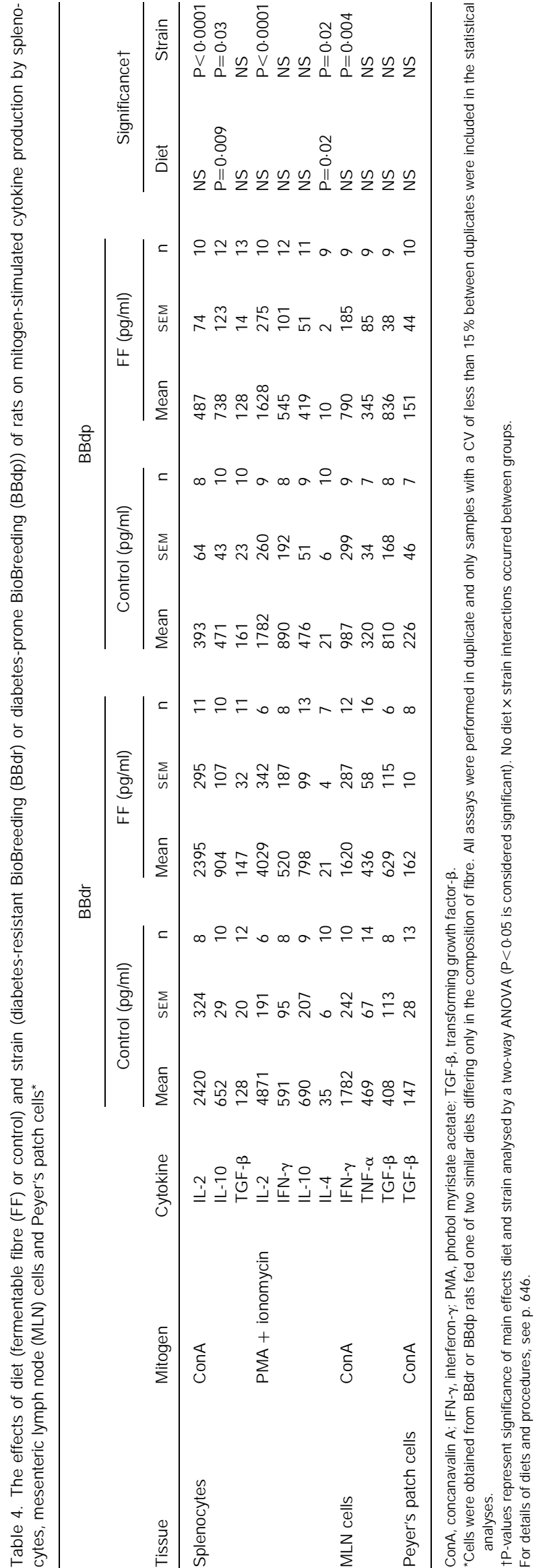


Germ-free mice have reduced numbers of IgA-producing cells in the intestine compared to conventionally housed mice (Crabbe et al. 1968), suggesting that the number of IgA-bearing cells in the lamina propria is antigen-dependent. Thus, an increased number of IgA + cells in the lamina propria of BBdp rats after FF feeding may be indicative of an increased exposure to antigen by cells in the Peyer's patches and lamina propria. Inulin is a well-established prebiotic fibre, which has been shown to increase the amount of lactobacilli and bifidobacteria in the intestine (Roland et al. 1995; B uddington et al. 2002). The changes in bacterial colonisation of the small intestine, as well as the large intestine, after feeding a diet containing inulin could potentially have stimulated B-cell activation in the Peyer's patches and subsequent migration to the lamina propria. $B$-cells can be exposed to antigen and activated in the Peyer's patches before they migrate to the lamina propria to secrete polymeric IgA (Kagnoff, 1993).

Several possible mechanisms could contribute to an increased antigen exposure in the Peyer's patches of BBdp rats. For example, a higher intestinal permeability has been reported in $\mathrm{BBdp}$ compared with $\mathrm{BBdr}$ rats prior to the age of disease onset, independent of diet (M eddings et al. 1999). Furthermore, increased intestinal inflammation, as evidenced by mucosal myeloperoxidase activity, has been observed in B Bdp rats before the age of disease onset possibly contributing to a greater intestinal permeability (Hardin et al. 2002). Feeding a diabetogenic diet to $B B d p$ rats further increases myeloperoxidase activity in the small intestine (Courtois et al. 2004b), thereby providing a mechanism by which intestinal B-cells might be exposed to antigen. Interestingly, the proportion of $0 \times 12+$ cells (B-cells) was significantly higher in the Peyer's patches from $B B d p$ rats fed the FF diet, consistent with the higher number of $\operatorname{lgA}+$ cells in the lamina propria.

The observation that feeding FF to BBdr rats did not affect the number of IgA + cells in the lamina propria is somewhat unusual. Other investigators have reported that feeding FF such as gum arabic, glucomannin, celfur, lactulose or curdlan, increased the number of IgA-bearing cells in the caecum of non-diabetic animals (Kudoh et al. 1998, 1999). We measured IgA expression in the jejunum, where the concentration of bacterial antigens is known to be lower than in the caecum (Hao \& Lee, 2004), and this may explain the lack of change with diet in the number of IgA-expressing cells in BBdr animals. It has been reported that feeding inulin/fructo-oligosaccharides increased the concentration of slgA in the ileum and caecum in rats (Roller et al. 2004) and $24 \mathrm{~h}$ faecal samples from mice (Hosono et al. 2003). In addition, Peyer's patch cells from mice fed fructo-oligosaccharides stimulated with a mitogen from gram-positive bacteria produced more IgA than controls (Hosono et al. 2003). We did not measure the amount of IgA produced and although we did not see a change in the number of IgA-producing cells in the jejunum of control rats, this does not exclude the possibility that FF might affect the production of slgA.

It has been demonstrated that feeding a diet containing FF can increase the proportion of CD8 + cells in the Peyer's patches (Field et al. 1999b), intra-epithelial lymphocytes in the small intestine (Field et al.1999b; Nagai et al. 2000; Ishizuka \& Tanaka, 2002), in the caecal mucosa (Ishizuka \& Tanaka, 2002) and in the colorectum ( $N$ agai et al. 2000). In the present study, we confirmed that feeding a diet containing $\mathrm{FF}$ results in a higher proportion of $\mathrm{CD} 8+$ cells in small intestinal Peyer's patches of BBdr animals compared with feeding a diet containing only cellulose as the fibre source. It might be predicted, based on movement between tissues, that phenotype changes observed in the Peyer's patches would be reflected in some way in the MLN. This was not the case in the present study and likely due to the very small proportion of CD8 + cells in Peyer's patches ( $<10 \%$ of total cells) compared to the much larger population of CD8 + cells in the MLN of these rats that comprised cells also migrating from the peripheral blood and intraepithelial regions of the gut.

As inulin is an established prebiotic, and in vitro and in vivo studies using probiotics lactobacilli and bifidobacteria have been shown to have effects on immune function (reviewed by Schley $\&$ Field, 2002), it is very likely that the effects on immune parameters measured in this study are in part due to a change in the intestinal microflora. Mechanisms by which a change in the microflora might affect immune function in healthy animals is through contact with live bacteria or bacterial components with immune cells in the gut, through bacterial metabolic by-products such as SCFA, and an alteration in the production of mucins (reviewed by Schley \& Field, 2002). The potential differences in microbial colonisation between strains were not addressed in this study. The consequences of such differences in colonisation remain to be elucidated.

The gastrointestinal tract has been implicated in the pathogenesis of diabetes in both human subjects and animal models (V aarala, 2002). In the present study, we have shown that BBdp rats have an abnormal response to a normal dietary ingredient when introduced at weaning. BBdr rats show evidence of immune activation after being fed a diet containing FF, while $B B d p$ rats show evidence of immune exposure without appropriate activation. It is possible that improper antigen handling and processing at a time when immune development is occurring may affect the later outcome of diabetes in these diabetes-prone rats if the appropriate environmental trigger is present.

\section{Acknowledgements}

We wish to acknowledge Susan Goruk, Donna Taylor, A rne V an A erde and Natasha Garewal for their technical help. This study was supported by an operating grant from the Canadian Diabetes Association and RoseM arie Stillie held a scholarship from the Muttart Diabetes and Research Training Centre, University of Alberta, Edmonton, Alberta.

\section{References}

Andoh A, Bamba T \& Sasaki M (1999) Physiological and anti-inflammatory roles of dietary fiber and butyrate in intestinal functions. JPEN J Parenter Enteral Nutr 23, S70-S73.

Beales PE, Elliot RB, Flohe S, Hill JP, Kolb H, Pozzilli P, Wang GS, Wasmuth $\mathrm{H} \&$ Scott FW (2003) A multi-centre, blinded international trial of the effect of $A(1)$ and $A(2)$ beta-casein variants on diabetes incidence in two rodent models of spontaneous Type I diabetes. Diabetologia $45,1240-1246$.

Buddington RK, K elly-Quagliana K, Buddington KK \& Kimura Y (2002) $N$ on-digestible oligosaccharides and defense functions: lessons learned from animal models. Br J Nutr 87, Suppl. 2, S231-S239.

Courtois P, Sener A, Scott FW \& M alaisse WJ (2004a) Disaccharidase activity in the intestinal tract of Wistar-Furth, diabetes-resistant and diabetes-prone BioBreeding rats. Br J Nutr 91, 201- 209. 
Courtois P, Sener A, Scott FW \& M alaisse WJ (2004b) Peroxidase activity in the intestinal tract of Wistar-Furth, $B B C$ and $B B d p$ rats. Diabetes Metab Res Rev 20, 305-314.

Crabbe PA, Bazin H, Eyssen $H$ \& Heremans JF (1968) The normal microbial flora as a major stimulus for proliferation of plasma cells synthesizing IgA in the gut. The germ-free intestinal tract. Int Arch Allergy Appl Immunol 34, 362-375.

Cummins A G, Eglinton BA, Gonzalez A \& Roberton DM (1994) Immune activation during infancy in healthy humans. J Clin Immunol 14, $107-115$.

Cummins AG, Labrooy JT \& Shearman DJ (1989) The effect of cyclosporin $A$ in delaying maturation of the small intestine during weaning in the rat. Clin Exp Immunol 75, 451- 456.

Cummins AG, Thompson FM \& Mayrhofer G (1991) Mucosal immune activation and maturation of the small intestine at weaning in the hypothymic (nude) rat. J Pediatr Gastroenterol Nutr 12, 361-368.

Edwards CA \& Parrett AM (2002) Intestinal flora during the first months of life: new perspectives. Br J Nutr 88, Suppl. 1, S11-S18.

Elliott RB, Reddy SN, Bibby NJ \& Kida K (1988) Dietary prevention of diabetes in the non-obese diabetic mouse. Diabetologia 31, 62-64.

Field CJ, Goruk S \& Glen S (1999a) Effect of diet on the development of the immune system in the BB rat. J Clin Biochem Nutr 26, 119-134.

Field CJ, M CBurney M I, M assimino S, Hayek M G \& Sunvold GD (1999b) The fermentable fiber content of the diet alters the function and composition of canine gut associated lymphoid tissue. Vet Immunol Immunopathol 72, 325-341.

Hao WL \& Lee YK (2004) Microflora of the gastrointestinal tract: a review. Methods $\mathrm{M}$ ol Biol 268, 491-502.

Hardin JA, Donegan L, Woodman RC, Trevenen C \& Gall DG (2002) Mucosal inflammation in a genetic model of spontaneous type I diabetes mellitus. Can J Physiol Pharmacol 80, 1064-1070.

Hosono A, Azawa A, Kato R, Ohnishi Y, Nakanishi Y, Kimura T \& Nakamura R (2003) Dietary fructooligosaccharides induce immunoregulation of intestinal IgA secretion by murine Peyer's patch cells. Biosci Biotechnol Biochem 67, 758-764.

Ishizuka S \& Tanaka S (2002) M odulation of CD8 + intraepithelial lymphocyte distribution by dietary fiber in the rat large intestine. Exp Biol Med (M aywood) 227, 1017- 1021.

Kagnoff M F (1993) Immunology of the intestinal tract. Gastroenterology $105,1275-1280$.

Kleessen B, Hartmann L \& Blaut M (2001) Oligofructose and long-chain inulin: influence on the gut microbial ecology of rats associated with a human faecal flora. Br J Nutr 86, 291-300.

K leessen B, H artmann L \& Blaut M (2003) Fructans in the diet cause alterations of intestinal mucosal architecture, released mucins and mucosaassociated bifidobacteria in gnotobiotic rats. $\mathrm{Br} J \mathrm{Nutr}$ 89, 597-606.

Kudoh K, Shimizu J, Ishiyama A, et al. (1999) Secretion and excretion of immunoglobulin A to cecum and feces differ with type of indigestible saccharides. J Nutr Sci Vitaminol (Tokyo) 45, 173-181.

Kudoh K, Shimizu J, Wada M, Takita T, Kanke Y \& Innami S (1998) Effect of indigestible saccharides on $B$ lymphocyte response of intestinal mucosa and cecal fermentation in rats. J Nutr Sci Vitaminol (Tokyo) 44, 103- 112.

Like AA, Butler L, Williams RM, A ppel MC, Weringer EJ \& Rossini AA (1982) Spontaneous autoimmune diabetes mellitus in the BB rat. Diabetes 31, 7- 13.

M acFarlane AJ, Burghardt K M, K elly J, Simell T, Simell O, A ltosaar I \& Scott FW (2003) A type 1 diabetes-related protein from wheat (Triticum aestivum). cDNA clone of a wheat storage globulin Glbl, linked to islet damage. J Biol Chem 278, 54-63.

Masjedi M, Tivey DR, Thompson FM \& Cummins A G (1999) Activation of the gut-associated lymphoid tissue with expression of interleukin-2 receptors that peaks during weaning in the rat. J Pediatr Gastroenterol Nutr 29, 556- 562 .

M eddings J B, J arand J, U rbanski SJ , Hardin J \& Gall DG (1999) Increased gastrointestinal permeability is an early lesion in the spontaneously diabetic BB rat. Am J Physiol 276, G951-G957.

M enezes JS, M ucida DS, Cara DC, et al. (2003) Stimulation by food proteins plays a critical role in the maturation of the immune system. Int Immunol 15, 447-455.

Nagai T, Ishizuka S, Hara H \& A oyama Y (2000) Dietary sugar beet fiber prevents the increase in aberrant crypt foci induced by gammairradiation in the colorectum of rats treated with an immunosuppressant. J Nutr 130, 1682- 1687.

Norris JM, Barriga K, K lingensmith $G$, et al. (2003) Timing of initial cereal exposure in infancy and risk of islet autoimmunity. J AM A 290, $1713-1720$

Ouwehand A, Isolauri E \& Salminen S (2002) The role of the intestinal microflora for the development of the immune system in early childhood. Eur J Nutr 41, Suppl. 1, I32-137.

Perrin IV, Marchesini M, Rochat FC, Schiffrin EJ \& Schilter B (2003) Oligofructose does not affect the development of type 1 diabetes mellitus induced by dietary proteins in the diabetes-prone B B rat model. Diabetes Nutr M etab 16, 94-101.

Pie S, Lalles JP, Blazy F, Laffitte J, Seve B \& Oswald IP (2004) W eaning is associated with an upregulation of expression of inflammatory cytokines in the intestine of piglets. J Nutr 134, 641-647.

Reimer RA, Glen S, Field CJ \& M CBurney MI (1998) Proglucagon and glucose transporter mRNA is altered by diet and disease susceptibility in 30-day-old biobreeding (B B) diabetes-prone and normal rats. P ediatr Res 44, 68- 73.

Rodriguez-Cabezas ME, Galvez J, Camuesco D, et al. (2003) Intestinal anti-inflammatory activity of dietary fiber (Plantago ovata seeds) in HLA-B 27 transgenic rats. Clin Nutr 22, 463- 471.

Roland N, Nugon-Baudon L, A ndrieux C \& Szylit O (1995) Comparative study of the fermentative characteristics of inulin and different types of fibre in rats inoculated with a human whole faecal flora. $\mathrm{Br}$ J Nutr 74, 239- 249.

Roller M, Rechkemmer G \& Watzl B (2004) Prebiotic inulin enriched with oligofructose in combination with the probiotics Lactobacillus rhamnosus and Bifidobacterium lactis modulates intestinal immune functions in rats. J Nutr 134, 153-156.

Schley PD \& Field CJ (2002) The immune-enhancing effects of dietary fibres and prebiotics. Br J Nutr 87, Suppl. 2, S221-S230.

Schmid S, K oczwara K, Schwinghammer S, L ampasona V, Ziegler AG \& Bonifacio E (2003) Delayed exposure to wheat and barley proteins reduces diabetes incidence in non-obese diabetic mice. Clin Immunol $111,108-118$.

Scott FW, M ongeau $R$, Kardish M, Hatina G, Trick KD \& Wojcinski Z (1985) Diet can prevent diabetes in the BB rat. Diabetes 34, 1059- 1062.

Thompson FM, M ayrhofer G \& Cummins A G (1996) Dependence of epithelial growth of the small intestine on $\mathrm{T}$-cell activation during weaning in the rat. Gastroenterology 111, 37-44.

V aarala 0 (2002) The gut immune system and type 1 diabetes. Ann N Y Acad Sci 958, 39- 46.

W aldmann TA (1993) The IL -2/IL -2 receptor system: a target for rational immune intervention. Immunol Today 14, $264-270$.

Y amada K, Tokunaga Y, Ikeda A, et al. (2003) Effect of dietary fiber on the lipid metabolism and immune function of aged Sprague-Dawley rats. Biosci Biotechnol Biochem 67, 429-433.

Ziegler A G, Schmid S, Huber D, Hummel M \& Bonifacio E (2003) Early infant feeding and risk of developing type 1 diabetes-associated autoantibodies. J AM A 290, 1721- 1728. 